\title{
Novel stationary phase for complexation gas chromatography originating from ionic liquid and metallomesogen
}

\author{
Kuan-Pin Huang, Tarun Kumar Misra, Guan-Ren Wang, Bao-Yu Huang, Chuen-Ying Liu* \\ Department of Chemistry, National Taiwan University, 1 Sec. 4, Roosevelt Road, Taipei 10617, Taiwan
}

\section{A R T I C L E I N F O}

\section{Article history:}

Received 13 August 2008

Received in revised form 7 November 2008

Accepted 10 November 2008

Available online 14 November 2008

\section{Keywords:}

Metallomesogen

Ionic liquid

Stationary phase

Complexation gas chromatography

\begin{abstract}
A B S T R A C T
A metallomesogen of a polycatenar oxazoline copper(II) complex, $\left[\mathrm{Cu}\left(S-\mathrm{C}_{12}\right)_{2}\right]$, that exhibited a columnar mesophase with a helical organization was prepared and employed as the stationary phase for the GC separation with polycyclic aromatic hydrocarbons (PAHs) as model compounds. For introducing the mesogen into the capillary column, an ionic liquid (BeMIM-TfO) was used as the vehicle. The results of thermal analyses and UV-vis spectroscopy indicated that some beneficial interactions occurred between the metallomesogen and the ionic liquid. Various parameters affecting the separation efficiency were studied. Different ratios of BeMIM-TfO and $\mathrm{Cu}\left(S-\mathrm{C}_{12}\right)_{2}(1: 0,1: 1,1: 2$ and $1: 3(\mathrm{w} / \mathrm{w}))$ were tested for the separation of the PAHs. As the amount of $\mathrm{Cu}\left(S-\mathrm{C}_{12}\right)_{2}$ was increased, complete separation could be achieved. The stationary phase with the ratio of $1: 1$ provided the most satisfactory result having average theoretical plate number of $5.2 \times 10^{3}$ plates $/ \mathrm{m}$. With an optimized temperature program, $11 \mathrm{PAH}$ mixtures were completely separated within $27 \mathrm{~min}$. The interaction between PAH and these fascinating and interesting stationary phases was discussed.
\end{abstract}

(C) 2008 Elsevier B.V. All rights reserved.

\section{Introduction}

Metallomesogens or metal-containing liquid crystals have attracted much interest in recent years for their unique properties derived from the presence of metal ions within anisotropic phases [1]. The central metal ion may provide properties not otherwise found in organic mesogens. They have been extensively studied over recent years in the material science [2-4]. Our interest is how to manipulate it to achieve the promising properties for analytical applications. A search for highly selective stationary phase is an important trend of chromatography. Witkiewicz et al. [5] reviewed the current state of the art in the use of liquid crystalline including metallomesogenic stationary phase for GC. Separations with the metallomesogenic phase can be considered as one example of the more popular complexation GC [6-9]. Both rod-like (calamitic) and disc-like (discotic) metallomesogens have been employed as the stationary phase for the separation of close-boiling isomers, which are difficult or impossible to separate on classical stationary phases [10-17]. Shape recognition and ligand exchange were found to be the predominant mechanisms in the separation processes. Notwithstanding their good separation properties, a major challenge in analytical practice is the choice of an appropriate metallomesogen and the processes for the incor-

\footnotetext{
* Corresponding author. Tel.: +8862 33661645; fax: +886223638543.

E-mail address: cyliu@ntu.edu.tw (C.-Y. Liu).
}

poration of it onto the capillary wall of a GC column. Therefore, only a few examples of their applications are found in the literature [5].

Ionic liquids (ILs) are ionic media resulting from the combination of organic cations and various anions. Over the past two decades, ILs have been widely used as green solvents, replacing traditional organic solvents. Intense worldwide research activity in the field of ILs is ongoing [18-22]. Extensive analytical chemistry investigations have been applied to liquid-liquid extraction [23], solid phase microextraction [24-26], sensors for a quartz crystal microbalance [27], and solvents for matrix-assisted laser desorption/ionization mass spectrometry [28-32]. Armstrong and co-workers have examined both theoretical and practical uses of ILs as stationary phases for GC [33-37]. Separations of enantiomeric mixtures have been achieved with the development of chiral ILs functioning as the chiral selector [38]. The unique properties of modern ILs such as high viscosity, broad liquid range, high thermo stability, low volatility, good wetting ability of the fusedsilica capillary, and the possibility of multiple interactions with a variety of solutes make ILs suitable candidates for GC stationary phases [39-47]. Achiral ILs have been introduced into the realm of chiral separations by dissolving the chiral selector in 1-butyl3-methylimidazolium chloride and 1-butyl-3-methylimidazolium hexafluorophosphate [44].

The mesogens we studied in previous work include metalthiolates and metal-carboxylates, and all of them require a vinyl group for the incorporation into the polysiloxane [10-17]. Despite 
extensive experience, the coating steps are often tedious and timeconsuming procedures. Columnar stationary phases, which could be formed from the stacking of discotic mesogens, are adapted to recognize flat-round-shaped analytes. Barberá et al. [48] have reported the use of oxazoline-derived ligands and metal coordination to prepare molecule with a phasmidic-like structure, which shows columnar organization in the liquid crystalline state. For introducing the metallomesogens onto the inner wall of a fused-silica capillary column, a thermally stable IL, 1-benzyl-3methylimidazolium triflate (BeMIM-TfO) was prepared [35]. By using the IL as a vehicle, the columnar polycatenar-copper complex was easily and smoothly applied as the stationary phase for capillary GC. To gain insight into the separation role of the metallomesogen, polycyclic aromatic hydrocarbons (PAHs) with $\pi$ electrons were chosen as model compounds for the column evaluation.

\section{Experimental}

\subsection{Apparatus}

Phase transitions were studied by differential scanning calorimetry (DSC) on LT-modulate DSC 2920 apparatus (TA instruments with TA 5100 control system, New Castle, DE, USA) operated at a heating rate of $10^{\circ} \mathrm{C} / \mathrm{min}$ under $\mathrm{N}_{2}$ flow $(50 \mathrm{~mL} / \mathrm{min})$. A TA-2950 type thermogravimetric analyzer was used for the measurement of sample thermal stability with nitrogen as the balance gas $(40 \mathrm{~mL} / \mathrm{min})$ and sample gas $(60 \mathrm{~mL} / \mathrm{min})$ over the temperature range from room temperature to $450^{\circ} \mathrm{C}$ at a rate of $10^{\circ} \mathrm{C} / \mathrm{min}$. Hot stage polarized light microscopy (FP82HT Thermosystem, Mettler Toledo, OH, USA) was carried out with a Nikon Eclipse E600 POL microscope (Melville, NY, USA) equipped with a Nikon E950 camera.

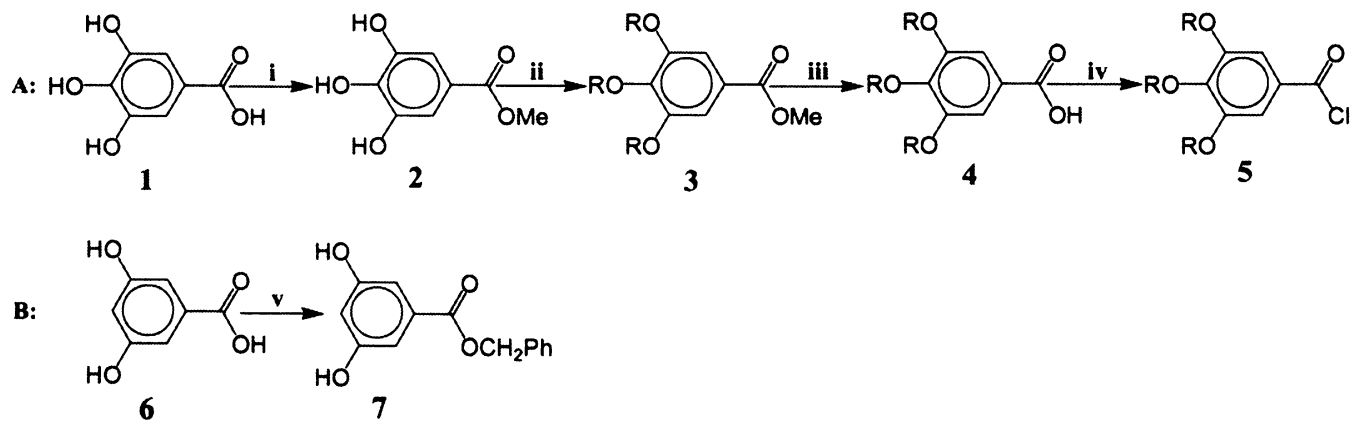

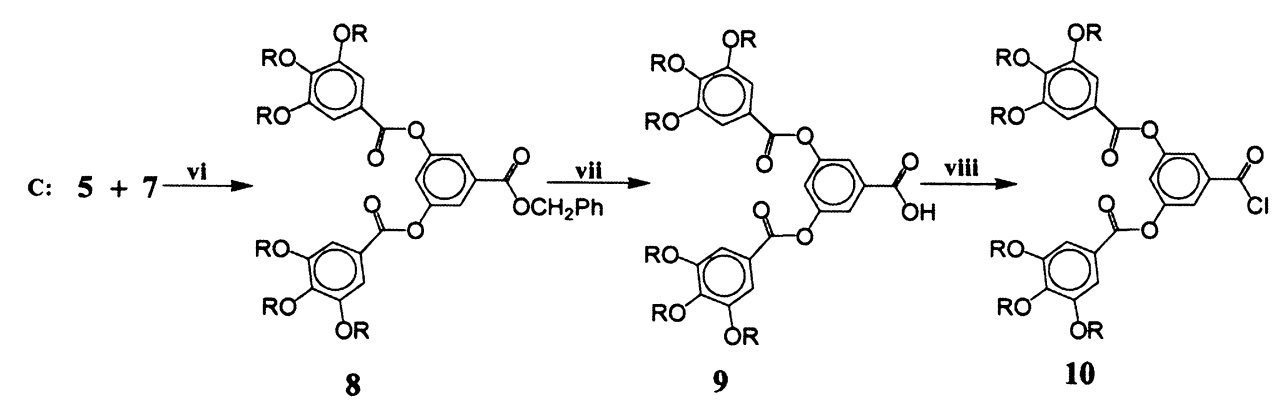<smiles>COc1ccc(COCCOc2ccc(CNCCOc3ccc(C4NC(C)CO4)cc3)cc2O)c(O)c1</smiles>

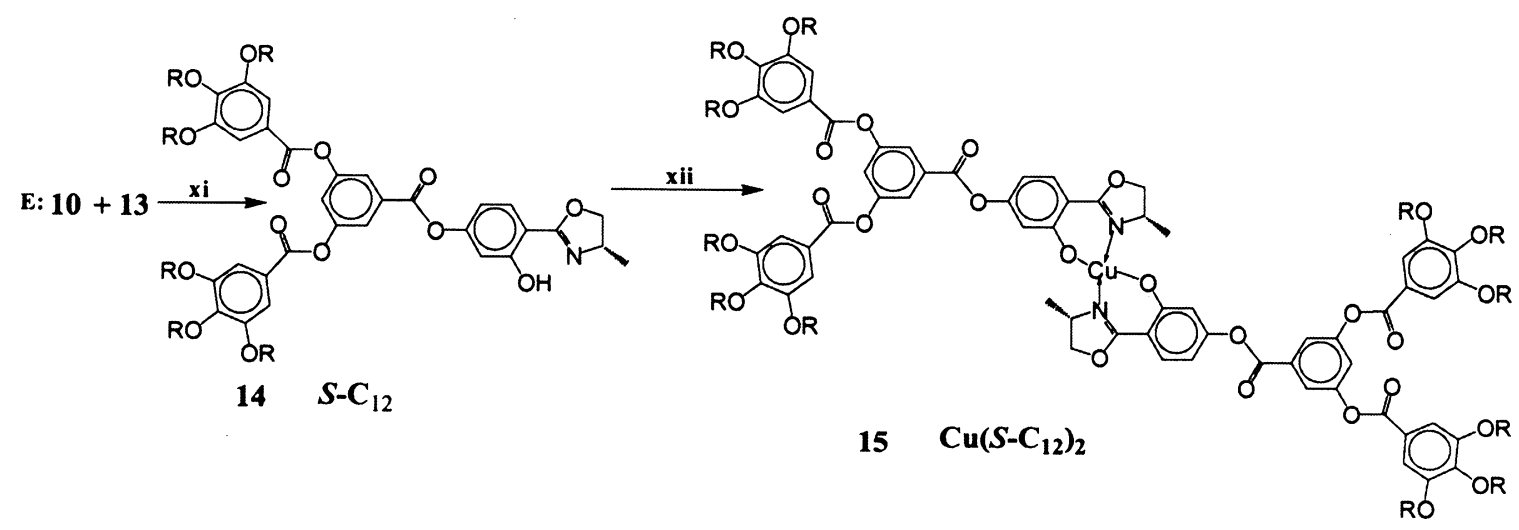

Fig. 1. Procedures for the preparation of metallomesogen. Reagents: (i) $\mathrm{H}_{2} \mathrm{SO}_{4} / \mathrm{MeOH}$; (ii) $n-\mathrm{C}_{12} \mathrm{H}_{25} \mathrm{Br} / \mathrm{K}_{2} \mathrm{CO}_{3} / \mathrm{DMF}$; (iii) $\mathrm{KOH} / \mathrm{H}_{2} \mathrm{O}-\mathrm{EtOH} / \mathrm{HCl}-\mathrm{DCM}$; (iv) $\mathrm{SOCl}$; (v) $\mathrm{PhCH}_{2} \mathrm{Br} / \mathrm{Na}_{2} \mathrm{CO}_{3} / \mathrm{DMF}$; (vi) $\mathrm{NEt}_{3} / \mathrm{CH}_{2} \mathrm{Cl}_{2}$; (vii) Pd(OH) $/$ C 20\%/cyclohexene; (viii) $\mathrm{SOCl}_{2}$; (ix) $\mathrm{NH}_{2} \mathrm{OH} \cdot \mathrm{HCl} / \mathrm{EtOH} / \mathrm{aq} \mathrm{Na}_{2} \mathrm{CO}_{3} / \mathrm{Ac}_{2} \mathrm{O} / \mathrm{KOH}$; (x) S-2-aminopropanol/ZnCl $/ \mathrm{PhCl}$; (xi) $\mathrm{Et}_{3} \mathrm{~N} / \mathrm{CH}_{2} \mathrm{Cl}_{2} ;$; xii) $\mathrm{Cu}(\mathrm{OAc})_{2} \cdot \mathrm{H}_{2} \mathrm{O} / \mathrm{EtOH}-\mathrm{CH}_{2} \mathrm{Cl}_{2} /$ acetone. 


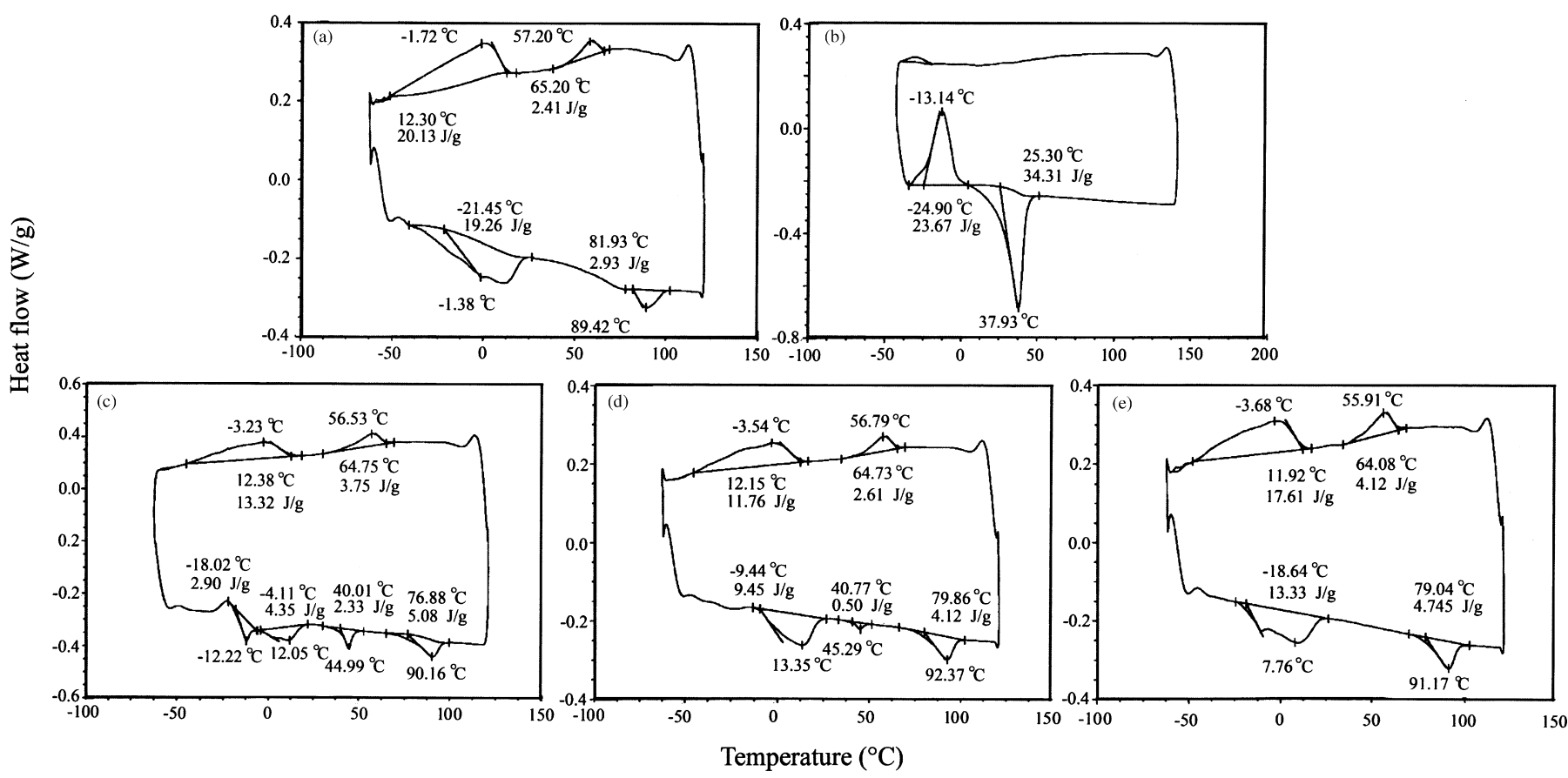

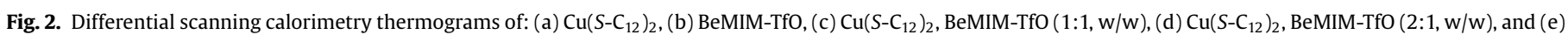
$\mathrm{Cu}\left(\mathrm{S}-\mathrm{C}_{12}\right)_{2}$, BeMIM-TfO $(3: 1, \mathrm{w} / \mathrm{w})$.

Column evaluation was performed by GC using a Shimadzu model 17A instrument (Kyoto, Japan) equipped with a capillary column split-injection system and a flame ionization detection (FID) system. Nitrogen was used as the carrier gas. The chromatograms were recorded and processed with Peak-ABC (Taipei, Taiwan) run by a Windows XP operating system. The separation was carried out on a fused-silica capillary column without deactivation (10 m $\times 0.25 \mathrm{~mm}$ I.D.) from Polymicro (Phoenix, AZ, USA).

\subsection{Chemicals and materials}

Purified water $(18 \mathrm{M} \Omega \mathrm{cm})$ from a Milli-Q water purification system (Millipore, Bedford, MA, USA) was used to prepare all solutions. The following materials were obtained from the indicated sources: 1-benzylimidazole, methyl trifluromethanesulfonate (Merck, Darmstadt, Garmany); ethyl acetate, dichloromethane and methanol (Mallinckrodt, Saint Louis, MO, USA); sodium hydroxide and hydrochloric acid (Riedel-de Haën, Seelze, Germany). Analytes include biphenyl (b.p. $255^{\circ} \mathrm{C}$; length to breadth ratio, L/B 1.748), dibenzofuran $\left(285^{\circ} \mathrm{C}\right), 1$-methylnaphthalene $\left(241-243^{\circ} \mathrm{C} ; 1.208\right)$, 2-methylnaphthalene $\left(241^{\circ} \mathrm{C} ; 1.381\right)$, naphthalene $\left(218^{\circ} \mathrm{C} ; 1.244\right)$ and phenanthrene $\left(336^{\circ} \mathrm{C} ; 1.569\right)$ (Merck, Darmstadt, Garmany); acenaphthene $\left(279^{\circ} \mathrm{C} ; 1.088\right)$, acenaphthylene $\left(280^{\circ} \mathrm{C} ; 1.072\right)$, fluorene $\left(298^{\circ} \mathrm{C} ; 1.542\right)$ and diphenylmethane $\left(265^{\circ} \mathrm{C} ; 1.651\right)$ (TCI, Tokyo, Japan); azulene $\left(242^{\circ} \mathrm{C}\right.$ ) (Acros, Geel, Belgium). Stock solutions of PAHs were prepared in methanol.

\subsection{Preparation of metallomesogen, $\mathrm{Cu}\left(\mathrm{S}-\mathrm{C}_{12}\right)_{2}$}

The preparatory route for all the compounds is depicted in Fig. 1. The preparation of the $S$-enantiomeric ligand, 4,5-dihydro2- $\left\{4^{\prime}-\left[\left(3^{\prime \prime}, 5^{\prime \prime}\right.\right.\right.$-bis(3,4,5-tridodecyloxybenzoyloxy)) benzoloxy $]-2^{\prime}-$ hydroxylphenyl $\}$-4-methyloxazole, $\left(S-C_{12}\right)(\mathbf{1 4})$ and its copper complex, $\mathrm{Cu}\left(\mathrm{S}-\mathrm{C}_{12}\right)_{2}(\mathbf{1 5})$ were previously reported [48]. Herein, we present the detailed and modified procedures used in the present synthesis. The preparation of 3,4,5-tridodecyloxybenzoic acid (4) was started with the esterification of 3,4,5-trihydroxybenzoic acid (gallic acid) (1) with methanol in the presence of sulfuric acid, $80 \%$, affording methyl-3,4,5-trihydroxybenzoate (2) [49] with a yield of $48 \%$. Alkylation of compound 2 at the phenolic-OH groups with $n$-dodecylbromide in $N, N$-dimethylformamide (DMF) at $70^{\circ} \mathrm{C}$ under $\mathrm{N}_{2}$ gave methyl-3,4,5-tridodecyloxybenzoate (3) [50] in 70\% yield. De-esterification of the compound 3 with potassium hydroxide in water-ethanol $(1: 3, v / v)$ followed by extraction with $\mathrm{HCl}$ $(0.6 \mathrm{M})-\mathrm{CH}_{2} \mathrm{Cl}_{2}$ mixture $(5: 3, \mathrm{v} / \mathrm{v})$ gave the acid, compound (4) [49] $80 \%$ yield. 3,5-Dihydroxybenzoic acid (6) was converted to its benzyl ester with benzyl bromide in DMF at room temperature, affording benzyl-3,5-dihydroxy benzoate (7) [51] with a yield of $74 \%$. The esterification of the compound 7 with $3,4,5-$ tridodecyloxybenzoylchloride (5) which was freshly prepared by refluxing the compound $\mathbf{4}$ in an excess of thionyl chloride, in the presence of triethylamine in dichloromethane at room temperature gave benzyl-3,5-bis(3,4,5-tridodecyloxybenzoyloxy)benzoate (8) with a yield of $64 \%$. De-benzylation of the compound 8 in the presence of $\mathrm{Pd}(\mathrm{OH})_{2} / \mathrm{C} 20 \%$ in cyclohexene led to its corresponding acid, 3,5-bis(3,4,5-tridodecyloxybenzoyloxy)benzoic acid (9) with a yield of 72\%. 2,4-Dihydroxybenzaldehyde (11) was first converted to the intermediate product, 2,4-dihydroxybenzaldoxime, from which the elimination of water with acetic anhydride followed by de-protection of the acetate group gave 2,4-dihydroxybenzonitrile (12), with a yield of $58 \%$. The condensation of the compound 12 with $S$-2-aminopropanol in the presence of zinc chloride in chlorobenzene gave stereospecifically selected 4,5-dihydro-2(2',4'-dihydroxyphenyl)-4-methyloxazole (13) (yield 54\%). The ligand, $S-C_{12}(14)$ was then prepared with a yield of $54 \%$ by the esterification of 4,5-dihydro-2-(2',4'-dihydroxyphenyl)-4-methyloxazole (13) with 3,5-bis(3,4,5-tridodecyloxybenzoyloxy)benzyl chloride (10) which was freshly prepared from the compound 9 by refluxing in an excess thionyl chloride. The ligand $\mathbf{1 4}$ was then subjected to coordination to copper(II) which resulted in the phasmidic-like-planar complex, $\mathrm{Cu}\left(S-\mathrm{C}_{12}\right)_{2}$ (15). All compounds were characterized by ${ }^{1} \mathrm{H}$ NMR and ${ }^{13} \mathrm{C}$ NMR spectroscopy. The copper complex was identified by elemental and thermoanalysis. 


\subsection{Preparation of BeMIM-TfO}

BeMIM-TfO was synthesized as described previously [35]. 1Benzylimidazolium was melted at $70^{\circ} \mathrm{C}$, and then an equimolar amount $(0.05 \mathrm{~mol})$ of methyl trifluromethanesulfonate was added slowly over $2 \mathrm{~h}$ under nitrogen. The dark yellow viscous liquid was washed by ethyl acetate three times.

\subsection{Column preparation}

Before coating, fused-silica capillary tubing was subjected to sodium hydroxide (30 min, $1 \mathrm{M}$ ) and hydrochloride acid (30 min, $1 \mathrm{M}$ ) washes. The capillary was then coated by the dynamic method. A solution of desired ratio of BeMIM-TfO and $\mathrm{Cu}\left(S-\mathrm{C}_{12}\right)_{2}$ in dichloromethane was introduced into the column under constant pressure of $0.101 \mathrm{MPa}$. The resultant product was then heated at $40{ }^{\circ} \mathrm{C}$ for $24 \mathrm{~h}$. The coated column was flushed with dry nitrogen for $1 \mathrm{~h}$, and then conditioned from 30 to $120^{\circ} \mathrm{C}$ at an incremental rate of $1{ }^{\circ} \mathrm{C} / \mathrm{min}$. After conditioning, the coated capillary was ready for use.

\section{Results and discussion}

\subsection{Characterization}

\subsubsection{Thermal properties}

Phase transitions of the mesogens were measured by DSC measurement and polarized light microscopy. Only the data of the second heating and the second cooling of DSC measurements are presented (Fig. 2). During the heating cycle, phase transitions for the $\mathrm{Cu}\left(\mathrm{S}-\mathrm{C}_{12}\right)_{2}$ were observed at -1.38 and $89.42^{\circ} \mathrm{C}$ with $\Delta H$ of 19.26 and $2.93 \mathrm{Jg}^{-1}$, respectively. As the sample was cooled from $120^{\circ} \mathrm{C}$, we obtained two exothermic peaks at -1.72 and $57.20^{\circ} \mathrm{C}$ with corresponding $\Delta H$ of 20.13 and $2.41 \mathrm{~J} \mathrm{~g}^{-1}$, respectively (Fig. 2a). We noted slight differences in both transition temperatures and $\Delta H$ values as compared with the data reported by Barberá et al. [48]. These discrepancies may be due to differences in the way the data were collected. In DSC measurements, the peak for the phase transition often shows heating rate dependence. The faster the heating rate, the higher the transition temperature becomes. Similarly, the $\Delta H$ values often show entropy dependence, with the higher entropy changes resulting in higher enthalpy changes.

The morphological observations under polarized light microscopy were mostly consistent with those described in the thermal analysis. Since $\mathrm{Cu}\left(S-\mathrm{C}_{12}\right)_{2}$ shows liquid crystal properties at room temperature, the heating process was started from $25^{\circ} \mathrm{C}$. The compound began to lose anisotropic property at $88^{\circ} \mathrm{C}$, and completely to form an isotropic liquid around $105^{\circ} \mathrm{C}$. A clearer phase transition was shown in the heating process than that in the cooling process.

The DSC measurement for the BeMIM-TfO indicated no thermal activity during the cooling process (Fig. 2b). In the heating process, one exothermic peak at $-13.14{ }^{\circ} \mathrm{C}$, and one endothermic peak at $37.93^{\circ} \mathrm{C}$ were observed, consistent with the values reported by Nishikawa et al. [52] who examined the melting and freezing behaviors of 1-butyl-3-methylimidazolium chloride and 1-butyl3-methylimidazolium bromide. The exothermic peak corresponds to freezing of the supercooled liquid. The existence of a stable, supercooled state has been reported for many ILs [53-55], and in the present study, the IL also shows this characteristic feature. The endothermic peak occurred close to the melting point, suggesting that the peak reflects the melting process. The broad peak in the melting process of IL may represent a pre-melting process. Some of the cations may change conformation to increase the fluctuation in the vibrations around the $\mathrm{C}-\mathrm{C}$ bonds.

The DSC measurements for the binary product of the metallomesogen with IL in various ratios were shown as Fig. 2c-e. It is apparent that the dilution factor blurred the phase transition range as compared with the signals from both the bare metallomesogens and the neat IL. There are four endothermic peaks occurred at $-12.22,12.05,44.99$ and $90.16^{\circ} \mathrm{C}$ (Fig. 2c). The presence of two extra endothermic peaks, as compared with the bare metallomesogen, implies some interactions occurred between the metallomesogen and the IL. When the amount of metallomesogen in the binary product was increased $(1: 2, w / w)$, only the second extra endothermic peak remained (Fig. 2d). A further increase in the amount of metallomesogen to $1: 3(\mathrm{w} / \mathrm{w})$, produced a DSC thermogram that was similar to that of the pure metallomesogen (Fig. 2e), except for the
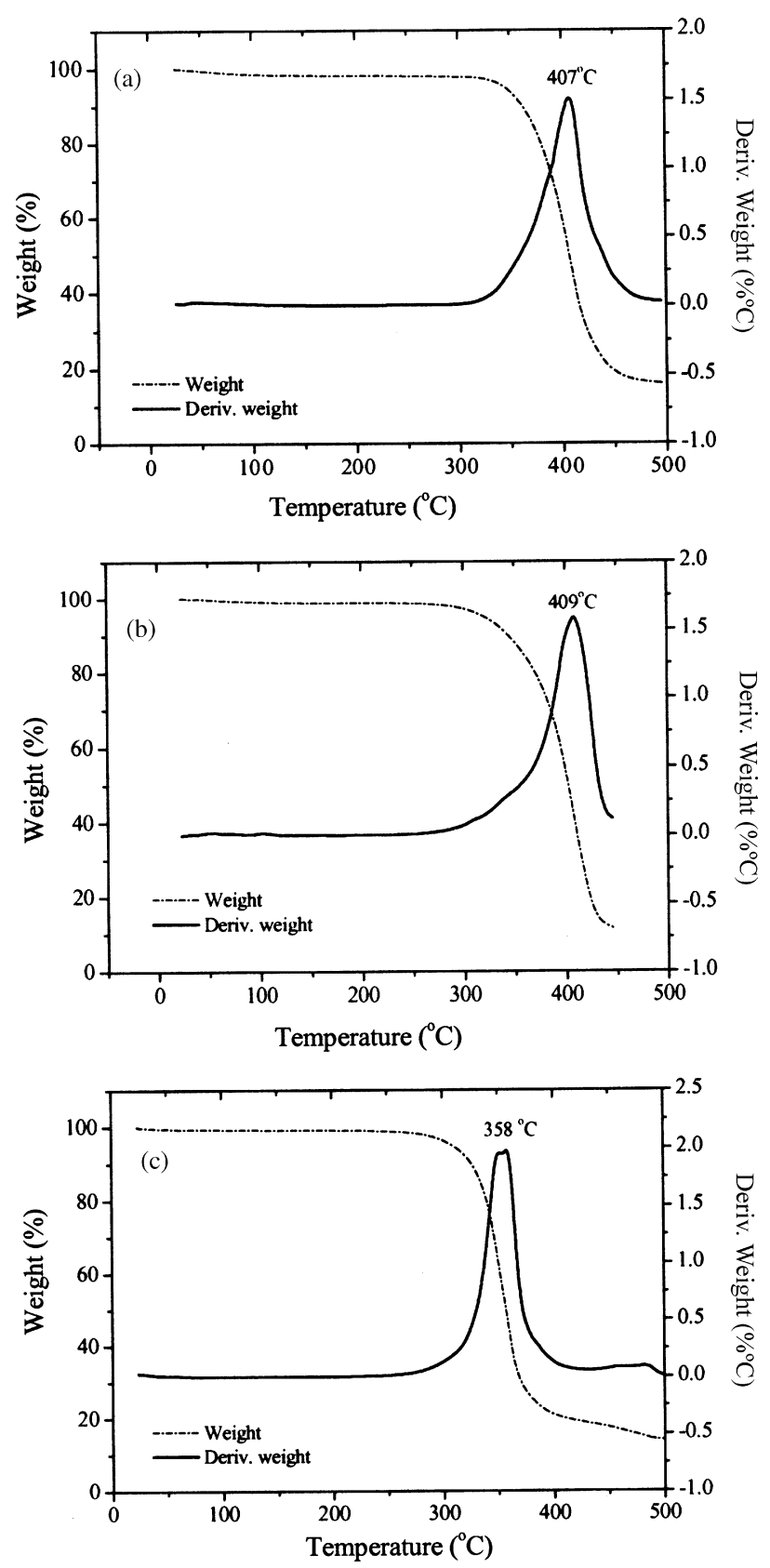

Fig. 3. Thermogravimetric analysis of: (a) $\mathrm{Cu}\left(S-\mathrm{C}_{12}\right)_{2}$, (b) BeMIM-TfO, (c) $\mathrm{Cu}\left(S-\mathrm{C}_{12}\right)_{2}$ BeMIM-TfO $(1: 1, w / w)$ 

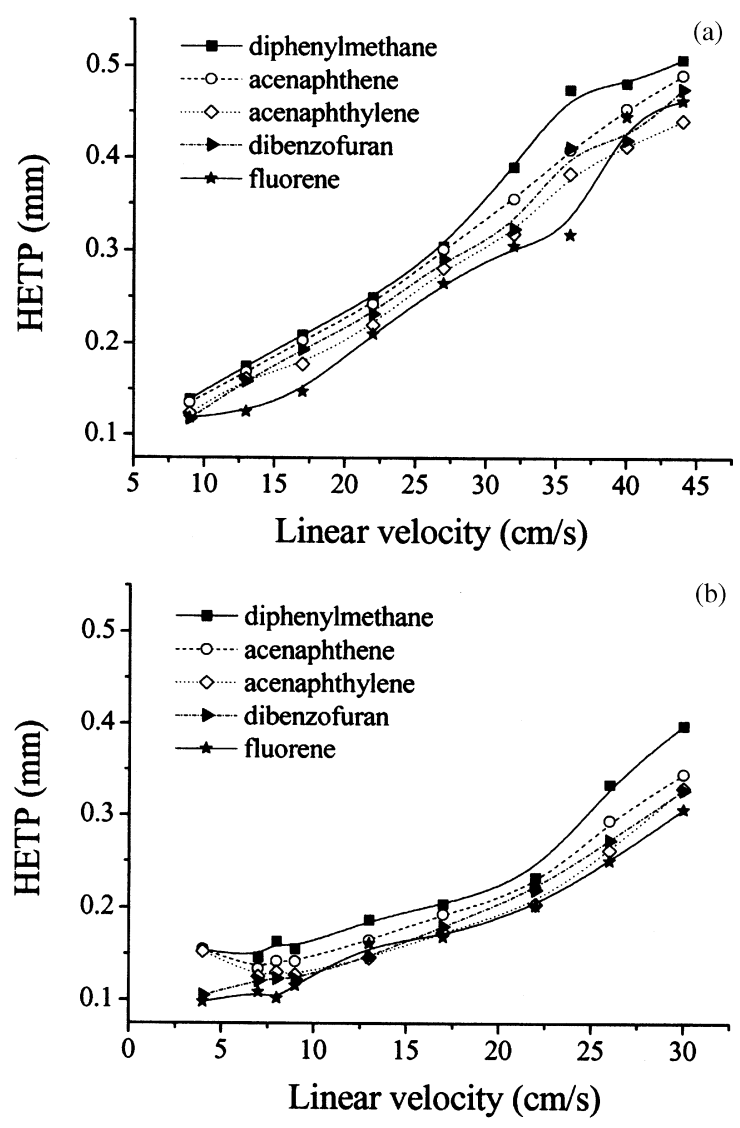

Fig. 4. The height equivalent to a theoretical plate (HETP) as a function of the linear velocity for the separation of PAHs. Stationary phase: $\mathrm{Cu}\left(S-\mathrm{C}_{12}\right)_{2}$ in $\mathrm{CH}_{2} \mathrm{Cl}_{2}(1 \%$, $\mathrm{w} / \mathrm{v})$ and BeMIM-TfO in $\mathrm{CH}_{2} \mathrm{Cl}_{2}(1 \%, \mathrm{w} / \mathrm{v})$ were immobilized on capillary column $(10 \mathrm{~m} \times 250 \mu \mathrm{m}$ I.D. ) as described in Section 2. Injection volume $1 \mu \mathrm{L}$; sample concentration $500 \mu \mathrm{g} / \mathrm{mL}$; injection temperature $220^{\circ} \mathrm{C}$; split ratio $1 / 20$; inlet pressure $20 \mathrm{kPa}$; oven temperature: (a) $100^{\circ} \mathrm{C}$ and (b) $120^{\circ} \mathrm{C}$.

slight increase of the phase transition temperature in the heating process, and a slight decrease of the temperature in the cooling process.

The thermal stability was also evaluated by TGA (Fig. 3). The decomposition temperatures of both BeMIM-TfO and $\mathrm{Cu}\left(S-\mathrm{C}_{12}\right)_{2}$ are above $400^{\circ} \mathrm{C}$. However, the binary compound of equal weight showed a lower decomposition temperature at $358^{\circ} \mathrm{C}$. The lower decomposition temperature may be due to complex formation between the IL and the metallomesogen.

\subsubsection{Optical properties}

The UV/vis spectra of metallomesogens $\mathrm{Cu}\left(S-\mathrm{C}_{12}\right)_{2}$ displayed a $\lambda_{\max }$ at $607 \mathrm{~nm}$ which can be attributed to the $\mathrm{d}-\mathrm{d}$ transitions of square planar copper(II) complexes (data not shown) [56]. For the $1: 1(\mathrm{w} / \mathrm{w})$ binary compound, $\lambda_{\max }$ was $612 \mathrm{~nm}$, a red shift of $5 \mathrm{~nm}$. To better understand the interaction, either BeMIM-TfO or $\mathrm{Cu}\left(S-\mathrm{C}_{12}\right)_{2}$ was used in the reference cell. With BeMIM-TfO as the reference compound, the $\lambda_{\max }$ underwent a red shift (from 607 to $617 \mathrm{~nm}$ ). This shift to longer wavelength indicated that with the formation of the IL-metal complex, a lesser difference between the energy levels of copper was found. However, there were no obvious changes in intensity with respect to concentration over this wavelength range in the BeMIM-TfO solution. This result implied that the wavelength shift resulted from the complex formation.

\subsection{Column performance evaluation}

In preliminary experiments that varied the injection temperature from 160 to $280^{\circ} \mathrm{C}$, the peak area of naphthalene appears highest at $220^{\circ} \mathrm{C}$. Thus, it was established as the optimum injection temperature for the PAHs.

\subsubsection{Flow rate}

At a constant oven temperature of $100^{\circ} \mathrm{C}$, an increase in inlet pressure from $10 \mathrm{kPa}$ (linear velocity, $9 \mathrm{~cm} / \mathrm{s}$ ) to $50 \mathrm{kPa}(44 \mathrm{~cm} / \mathrm{s}$ ) resulted in faster elution times. At inlet pressure less than $30 \mathrm{kPa}$ $(27 \mathrm{~cm} / \mathrm{s})$, all analytes were completely separated, except phenanthrene which was not detected within the experimental time. Increasing the oven temperature to $120^{\circ} \mathrm{C}$ gave faster elution for most analytes, and eventually, at an inlet pressure of $50 \mathrm{kPa}$ $(44 \mathrm{~cm} / \mathrm{s})$, phenanthrene eluted after approximately $1 \mathrm{~h}$.

Plots of the plate height as a function of linear velocity revealed that plate height less than $0.20 \mathrm{~cm}$ was found at a linear velocity over the range of $4-17 \mathrm{~cm} / \mathrm{s}$ for most analytes (Fig. 4). The optimal inlet pressure was thus chosen as $20 \mathrm{kPa}(17 \mathrm{~cm} / \mathrm{s})$.

\subsubsection{Isothermal separation}

The effect of the oven temperature on the separation of PAHs was examined over the temperature range of $80-130^{\circ} \mathrm{C}$. At oven temperatures lower than $80^{\circ} \mathrm{C}$, extended analysis time was needed, while at temperatures higher than $110^{\circ} \mathrm{C}$, poor resolution for the four earliest eluted analytes occurred. The most satisfactory results were obtained at an oven temperature of $100^{\circ} \mathrm{C}$ (Fig. 5). The separation efficiency was around 5000 plates/m (Table 1 ). With a relative standard deviation (RSD) of the retention time of less than $1 \%$, the

Table 1

Separation efficiency of the capillary column with binary product as stationary phase at various oven temperatures ${ }^{\mathrm{a}}$.

\begin{tabular}{|c|c|c|c|c|c|c|c|c|c|c|c|c|}
\hline \multirow[t]{2}{*}{ Analyte } & \multicolumn{4}{|c|}{ Retention time (RSD, \%) (min) } & \multicolumn{4}{|c|}{ Resolution } & \multicolumn{4}{|c|}{$N(\text { plates } / \mathrm{m})^{\mathrm{c}}$} \\
\hline & $85^{\circ} \mathrm{C}$ & $90^{\circ} \mathrm{C}$ & $95^{\circ} \mathrm{C}$ & $100^{\circ} \mathrm{C}$ & $85^{\circ} \mathrm{C}$ & $90^{\circ} \mathrm{C}$ & $95^{\circ} \mathrm{C}$ & $100^{\circ} \mathrm{C}$ & $85^{\circ} \mathrm{C}$ & $90^{\circ} \mathrm{C}$ & $95^{\circ} \mathrm{C}$ & $100^{\circ} \mathrm{C}$ \\
\hline Naphthalene & $8.8(0.52)$ & $7.4(0.91)$ & $6.3(0.34)$ & $5.4(0.57)$ & - & - & - & - & 5400 & 4300 & 4400 & 4000 \\
\hline 2-Methylnaphthalene & $16.6(0.24)$ & $13.5(0.72)$ & $11.1(0.19)$ & $9.2(0.74)$ & 10.7 & 9.7 & 9.3 & 8.8 & 4900 & 4700 & 4800 & 4300 \\
\hline 1-Methylnaphthalene & $18.5(0.20)$ & $15.0(0.70)$ & $12.3(0.23)$ & $10.2(0.73)$ & 1.9 & 1.9 & 1.8 & 1.7 & 4800 & 4600 & 4800 & 4300 \\
\hline Azulene & $23.7(0.21)$ & $19.1(0.64)$ & $15.6(0.12)$ & $12.8(0.85)$ & 4.4 & 4.3 & 4.2 & 4.2 & 5500 & 5400 & 5300 & 4800 \\
\hline Biphenyl & $28.1(0.13)$ & $22.3(0.56)$ & $17.8(0.24)$ & $14.4(0.88)$ & 3.1 & 2.8 & 2.3 & 2.1 & 5300 & 5100 & 4900 & 5000 \\
\hline Diphenyl methane & $35.8(0.49)$ & $28.2(0.50)$ & $22.4(0.32)$ & $17.9(0.87)$ & 4.4 & 4.2 & 4.0 & 3.7 & 4900 & 4900 & 5000 & 4800 \\
\hline Acenaphthene & $55.3(0.54)$ & $43.6(0.34)$ & $34.5(0.32)$ & $27.4(0.89)$ & 7.2 & 7.5 & 7.9 & 7.4 & 5200 & 4600 & 5500 & 4900 \\
\hline Acenaphthylene & $62.4(0.52)$ & $49.2(0.46)$ & $38.8(0.43)$ & $31.0(0.87)$ & 2.2 & 2.2 & 2.3 & 2.2 & 6100 & 4900 & 5800 & 5600 \\
\hline Dibenzofuran & $79.5(0.50)$ & $61.8(0.20)$ & $48.5(0.53)$ & $38.2(0.85)$ & 4.7 & 4.2 & 4.0 & 3.8 & 6200 & 5600 & 5500 & 5200 \\
\hline Fluorene & $126.8(0.61)$ & $97.8(0.67)$ & $75.0(1.04)$ & $58.7(0.84)$ & 9.2 & 7.9 & 8.1 & 8.0 & 6500 & 7900 & 6000 & 6800 \\
\hline
\end{tabular}

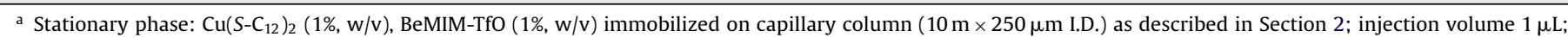
sample concentration $500 \mu \mathrm{g} / \mathrm{mL}$; injection temperature $220^{\circ} \mathrm{C}$; split ratio $1 / 20$; inlet pressure $20 \mathrm{kPa}$.

b Relative standard deviation $(N=3)$.

c Theoretical plate number, $N=5.54\left(t_{\mathrm{R}} / w_{1 / 2}\right)^{2}$. 


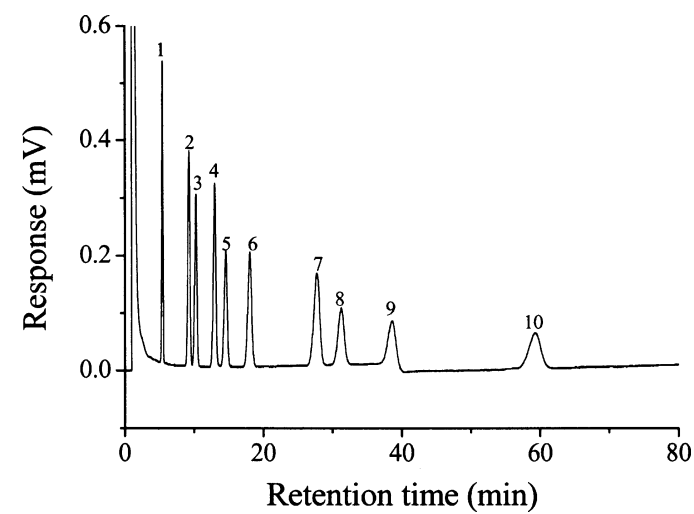

Fig. 5. Gas chromatogram for the separation of PAHs. Conditions as in Fig. 4, except at oven temperature of $100^{\circ} \mathrm{C}$. Peaks: 1 =naphthalene; $2=2$-methylnaphthalene; 3=1-methylnaphthalene; $\quad 4$ =azulene; $\quad 5$ =biphenyl; $\quad 6$ =diphenylmethane; 7 = acenaphthene; 8 = acenaphthylene; 9 = dibenzofuran; 10 = fluorene.

column was highly reproducible. Under these conditions, however, phenanthrene was still not eluted within $2 \mathrm{~h}$.

To elucidate whether the properties of the mesogen were still retained after it was introduced into the support, the dependence of the retention factor on the reciprocal absolute temperature was studied. These van't Hoff plots revealed not clear distinct inflection point (Fig. 6). The closely parallel lines indicate a similar solubility among the tested analytes in the binary product of metallomesogen and IL. Meanwhile no significant variations of the analyte solubility between mesogenic and isotropic phases were exhibited, and the mentioned properties resulted in no strong breaks in this plot.

\subsubsection{Effect of metallomesogen on the separation of PAHs}

Because of the wide boiling range of the analytes, it was difficult to separate all 11 compounds isothermally within a reasonable time. Hence, several assays of temperature programming were performed. One of the best conditions was as follows: $100^{\circ} \mathrm{C}$ for $3 \mathrm{~min}$, then heating from 100 to $150^{\circ} \mathrm{C}$ at a rate of $3^{\circ} \mathrm{C} / \mathrm{min}$, and then holding the temperature at $150^{\circ} \mathrm{C}$ for $1 \mathrm{~min}$, then heating to a final temperature of $190^{\circ} \mathrm{C}$ at a rate of $10^{\circ} \mathrm{C} / \mathrm{min}$. A complete separation of the 11 PAHs was achieved within 27 min (Fig. 7a).

Holding the amount of BeMIM-TfO constant ( $1 \%$ in $\left.\mathrm{CH}_{2} \mathrm{Cl}_{2}, \mathrm{w} / \mathrm{v}\right)$, the ratio of $\mathrm{Cu}\left(S-\mathrm{C}_{12}\right)_{2}$ was varied from 1 to $3 \%$ in $\mathrm{CH}_{2} \mathrm{Cl}_{2}$, w/v (Fig. $7 \mathrm{a}-\mathrm{c})$. With $\mathrm{Cu}\left(\mathrm{S}-\mathrm{C}_{12}\right)_{2}$ at $1 \%(\mathrm{w} / \mathrm{v})$, all 11 of the PAHs were baseline separated. But, as the amount of $\mathrm{Cu}\left(S-\mathrm{C}_{12}\right)_{2}$ was increased

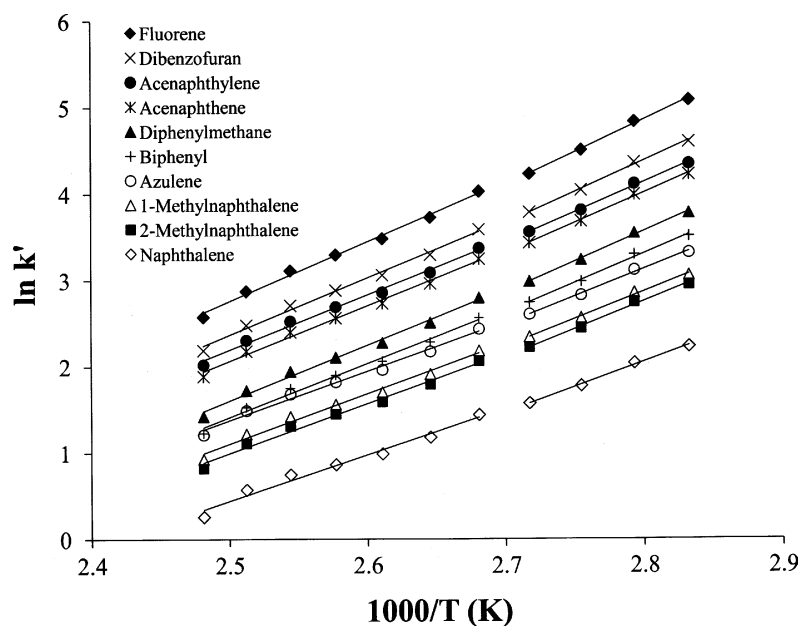

Fig. 6. van't Hoff plot for the separation PAHs. Conditions as in Fig. 4.
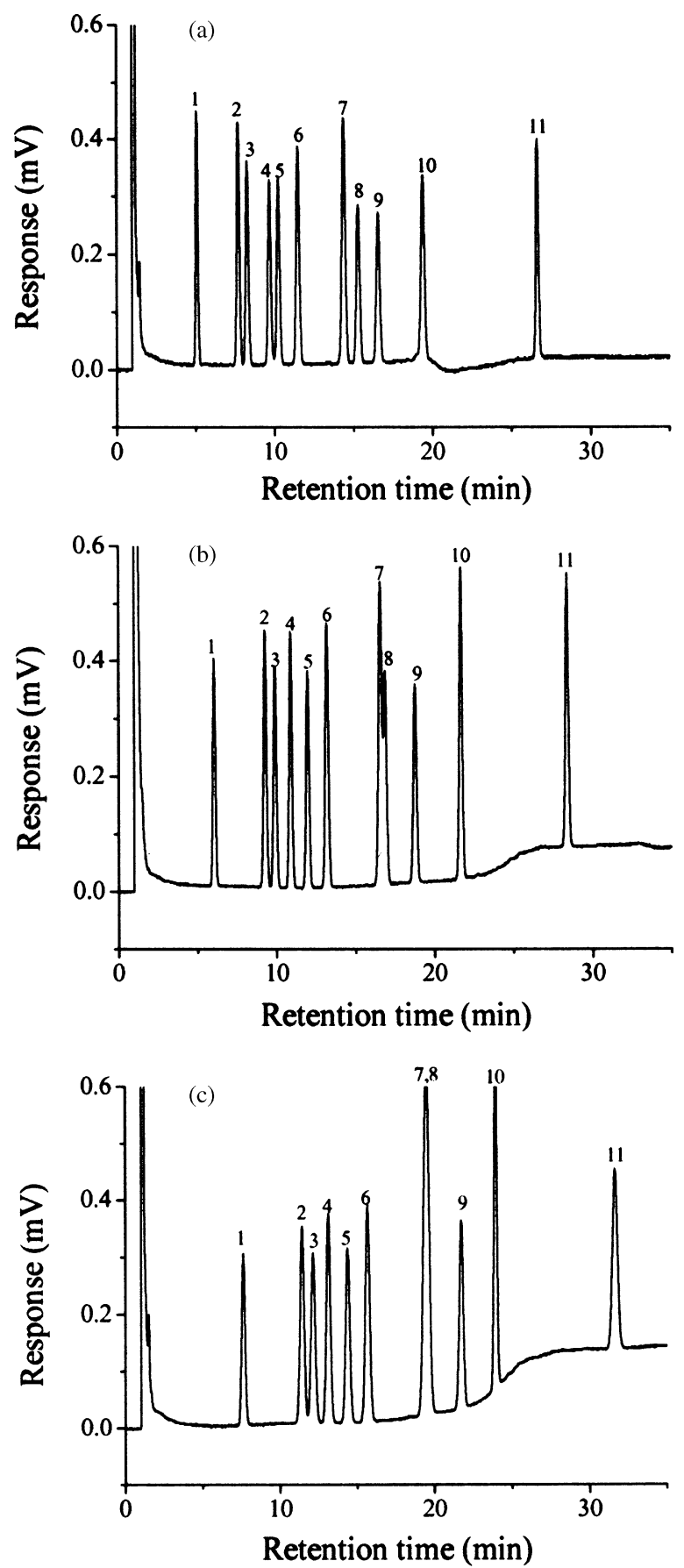

Fig. 7. Programmed-temperature separation of PAHs with different composition of binary phase. Conditions as in Fig. 4, except oven temperature: hold at $100^{\circ} \mathrm{C} \times 3 \mathrm{~min}$, then heated at $3^{\circ} \mathrm{C} / \mathrm{min}$ to $150{ }^{\circ} \mathrm{C}$, hold at $150^{\circ} \mathrm{C} \times 1 \mathrm{~min}$, then heated at $10^{\circ} \mathrm{C} / \mathrm{min}$ to $190^{\circ} \mathrm{C}$, and stationary phases shown as follows: (a) $\mathrm{Cu}\left(S-\mathrm{C}_{12}\right)_{2}$ in $\mathrm{CH}_{2} \mathrm{Cl}_{2}(1 \%, \mathrm{w} / \mathrm{v}) / \mathrm{BeMIM}-\mathrm{TfO}$ in $\mathrm{CH}_{2} \mathrm{Cl}_{2}(1 \%, \mathrm{w} / \mathrm{v})$, (b) $\mathrm{Cu}(\mathrm{S}$ $\left.\mathrm{C}_{12}\right)_{2}$ in $\mathrm{CH}_{2} \mathrm{Cl}_{2}(2 \%, \mathrm{w} / \mathrm{v}) / \mathrm{BeMIM}-\mathrm{TfO}$ in $\mathrm{CH}_{2} \mathrm{Cl}_{2}(1 \%, \mathrm{w} / \mathrm{v})$, and (c) $\mathrm{Cu}\left(\mathrm{S}-\mathrm{C}_{12}\right)_{2}$ in $\mathrm{CH}_{2} \mathrm{Cl}_{2}(3 \%, \mathrm{w} / \mathrm{v}) / \mathrm{BeMIM}-\mathrm{TfO}$ in $\mathrm{CH}_{2} \mathrm{Cl}_{2}(1 \%$, w/v). Peaks: $1=$ naphthalene; 2=2-methylnaphthalene; 3=1-methylnaphthalene; 4 =azulene; 5 =biphenyl; 6 =diphenylmethane; 7 =acenaphthene; 8 =acenaphthylene; $9=$ dibenzofuran; 10 = fluorene; 11 = phenanthrene.

to $2 \%(\mathrm{w} / \mathrm{v})$ and $3 \%(\mathrm{w} / \mathrm{v})$, resolution was lost and acenaphthylene and acenaphthene were eluted in a single peak. The poorer efficiency of the 2 and 3\% metallomesogen stationary phases may be due to the poorer mass transfer of the thicker film. In addition, a column bleed was detected at $190^{\circ} \mathrm{C}$ by the baseline hump (Fig. $7 \mathrm{~b}$ and 


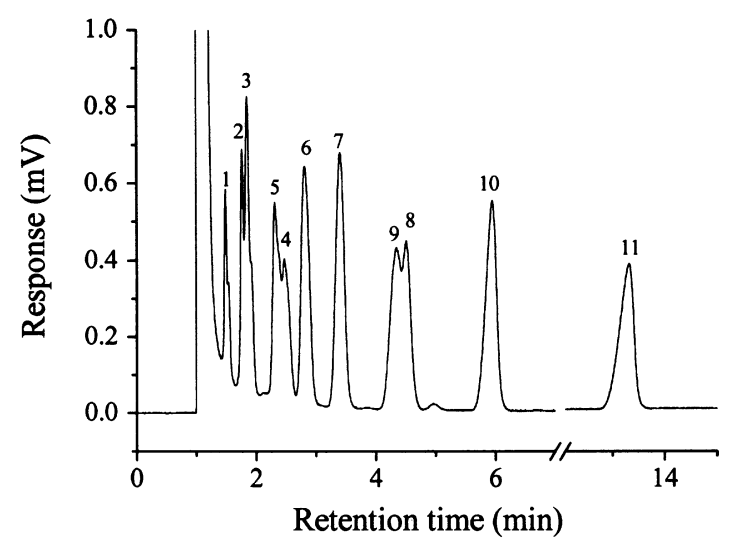

Fig. 8. Programmed-temperature separation of PAHs with neat IL stationary phase. Conditions as in Fig. 7, except stationary phase: BeMIM-TfO in $\mathrm{CH}_{2} \mathrm{Cl}_{2}$ (1\%, w/v). Peaks: 1 =naphthalene; $2=2$-methylnaphthalene; 3 . 1-methylnaphthalene; $4=$ azulene; 5 = biphenyl; 6 = diphenylmethane; 7 = acenaphthene; 8 = acenaphthylene; 9 = dibenzofuran; 10 = fluorene; 11 = phenanthrene.

c). The discrepancy between the results of GC and TGA may be the result of lower viscosity of the binary phase and more challenging solubilization of $\mathrm{Cu}\left(\mathrm{S}-\mathrm{C}_{12}\right)_{2}$ into the IL matrix.

\subsubsection{Effect of IL on the separation of PAHs}

To better understand the separation mechanism, the retention behaviors for PAHs on neat IL were also studied (Fig. 8). Fewer peaks were found as compared with the results exhibited by the binary product (Fig. 7a). Three pairs of analytes failed to achieve baseline separation, including 2-methylnaphthalene and 1-methylnaphthalene, azulene and biphenyl, and the pair of dibenzofuran and acenaphthylene. Meanwhile, shorter retention time was shown. The molecular recognition properties of the metallomesogen apparently contributed to the complete separation of the 11 analytes (Fig. 7a).

\subsection{Separation mechanism}

Phasmidic liquid crystal phases are generally formed by materials that have molecular structures which are intermediate in shape between discs (discotic) and rods (calamitic) [57]. PAHs, having $\pi$ electrons in the benzene ring, could form complexes with the central metal atom of the metallomesogen $[58,59]$. This property resulted in an improved interaction and, thus, greater retention of the analytes with the binary stationary phase than with the neat IL was shown (Fig. 8). Acenaphthylene has one more double bond than acenaphthene, and it was eluted after acenaphthene, although the $\mathrm{L} / \mathrm{B}$ ratios are identical. This difference can be explained by the distinct property as occurs in complexation GC $[5,7,8]$. The results shown in Table 1 indicate that both resolution and number of theoretical plate are better at liquid crystalline phase than those at $100^{\circ} \mathrm{C}$. By considering the analysis time, however, a higher oven temperature but close to the liquid crystalline temperature was adopted. The structural isomer of 1-methylnaphthalene and 2-methylnaphthalene could be separated. The shape selectivity mechanism indeed exists in our binary stationary phase. The chromatographic results show that 1-methylnaphthalene was more compatible with the metallomesogen considering the close boiling point possessed by the two isomers.

Azulene is an isomer of naphthalene, but with significantly different properties. Similar to naphthalene, it is a planar hydrocarbon possessing $10 \pi$ electrons, but aside from two electronically neutral resonance structures, a possible zwitterionic form also exists with a negatively charged five-membered and a positively charged seven-membered ring [60]. This property resulted in a much higher b.p. $\left(242^{\circ} \mathrm{C}\right)$ than that of naphthalene $\left(218^{\circ} \mathrm{C}\right)$. Although the b.p. of azulene close to the geometric isomer of 1-methylnaphthalene (241-243 $\left.{ }^{\circ} \mathrm{C}\right)$ and 2 -methylnaphthalene $\left(241^{\circ} \mathrm{C}\right)$, complete separation of these analytes could be achieved using this novel column. By further considering the chromatograms, the elution order of azulene $\left(242^{\circ} \mathrm{C}\right)$ and biphenyl $\left(255^{\circ} \mathrm{C}\right)$ in the binary phase (Fig. 7$)$ was different from that in the neat IL phase (Fig. 8). The later eluted azulene in IL phase indicated that IL has a greater polarity compared with the binary phase.

\section{Conclusions}

ILs can be designed to have the preferred properties of viscosity, thermal stability, and specific solute-IL interactions simply by changing the nature of the cation or anion. By using ILs as vehicles, the extensive application of metallomesogens to separation science holds great promise. Initially, we considered the role of IL to be as an inert solvent useful for transferring the metallomesogen to the bare fused-silica capillary. However, our spectroscopic studies indicated that some beneficial interactions occurred between these two materials with the satisfactory production of a binary product originating from the metallomesogen and the IL. With PAHs as model compounds, we achieved improved separation efficiency even for structural isomers by the use of the binary product as the stationary phase instead of the neat IL. With nitrogen as carrier gas, we propose that the stationary phase provides ligand exchange, in addition to the intrinsic properties of ILs which include dispersion force and the aromatic $\pi$-system of the cationic moiety [61]. The newly synthesized binary product is capable of providing unique selectivity for a wide variety of molecules especially those having $\pi$ electrons or electron donating elements even at lower oven temperature with shorter column length compared with the conventional stationary phase. It is really a promising and interesting stationary phase for capillary GC. The potentials for the wide use of this novel stationary phase are now undergoing.

\section{Acknowledgement}

The authors thank the Nation Science Council of Taiwan for financial support (Grant Nos. NSC 96-2113-M-002-023-MY3 and NSC 95-2113-M-002-002).

\section{References}

[1] B. Donnio, D. Guillon, R. Deschenaux, D. Bruce, in: J.A. McCleverty, T.J. Meyer (Eds.), From the Molecular to the Nanoscale: Synthesis, Structure, and Properties (Comprehensive Coordination Chemistry II), vol. 7, Elsevier, Oxford, 2004.

[2] S. Polarz, R. Regenspurger, J. Hartmann, Angew. Chem. Int. Ed. 46 (2007) 2426.

[3] L. Oriol, J.L. Serrano, Angew. Chem. Int. Ed. 44 (2005) 6618.

[4] D. Pucci, I. Aiello, A. Bellusci, A. Crispini, I. De Franco, M. Ghedini, M. La Deda, Chem. Commun. (2008) 2254.

[5] Z. Witkiewicz, J. Oszczudłowski, M. Repelewicz, J. Chromatogr. A 1062 (2005) 155.

[6] D. Cagniant (Ed.), Complexation Chromatography, Marcel Dekker, New York, 1992.

[7] V. Schurig, in: K. Jinno (Ed.), Chromatographic Separations Based on Molecular Recognition, Wiley-VCH, New York, 1996, p. 371 (Ch. 7).

[8] Z.J. Jiang, V. Schurig, J. Chromatogr. A 1186 (2008) 262.

[9] V. Schurig, J. Chromatogr. A 965 (2002) 315.

[10] C.C. Hu, C.Y. Liu, Anal. Chim. Acta 332 (1996) 23.

[11] C.Y. Liu, C.C. Hu, C.L. Yang, J. Chromatogr. A 773 (1997) 199.

[12] C.Y. Liu, J.L. Chen, C.C. Shiue, K.T. Liu, J. Chromatogr. A 862 (1999) 65

[13] C.Y. Liu, C.C. Hu, J.L. Chen, K.T. Liu, Anal. Chim. Acta 384 (1999) 51.

[14] C.Y. Liu, S.H. Yang, M.H. Chau, C.C. Shiue, J. Chromatogr. A 933 (2001) 117.

[15] C.T. Chou, Y.F. Pai, C.C. Lin, T.K. Misra, C.Y. Liu, J. Chromatogr. A 1043 (2004) 255

[16] J.L. Chen, C.Y. Liu, Anal. Chim. Acta 548 (2005) 73.

[17] J.L. Chen, C.Y. Liu, J. Chromatogr. A 1161 (2007) 269.

[18] M. Smiglak, A. Metlen, R.D. Rogers, Acc. Chem. Res. 40 (2007) 1182.

[19] K. Binnemans, Chem. Rev. 105 (2005) 4148. 
[20] P. Wasserscheid, T. Welton (Eds.), Ionic Liquids in Synthesis, 2nd ed., Wiley-VCH, Weinheim, 2008.

[21] J.L. Anderson, D.W. Armstrong, G.T. Wei, Anal. Chem. 78 (2006) 2892

[22] A. Berthod, M. Ruiz-Ángel, S. Carda-Broch, J. Chromatogr. A 1184 (2008) 6.

[23] J.H. Wang, D.H. Cheng, X.W. Chen, Z. Du, Z.L. Fang, Anal. Chem. 79 (2007) 620.

24] V. Pino, Q.Q. Baltazar, J.L. Anderson, J. Chromatogr. A 1148 (2007) 92.

[25] J.F. Liu, N. Li, G.B. Jiang, J.M. Li, J.A. Jonsson, M.J. Wen, J. Chromatogr. A 1066 (2005) 27.

[26] Y.N. Hsieh, P.C. Huang, I.W. Sun, T.J. Whang, C.Y. Hsu, H.H. Huang, C.H. Kuei, Anal. Chim. Acta 557 (2006) 321

[27] X.X. Jin, L. Yu, D. Garcia, R.X. Ren, X.Q. Zeng, Anal. Chem. 78 (2006) 6980.

[28] G. Stubiger, O. Belgacem, Anal. Chem. 79 (2007) 3206.

[29] D.W. Armstrong, L.K. Zhang, L.F. He, M.L. Gross, Anal. Chem. 73 (2001) 3679.

[30] S. Carda-Broch, A. Berthod, D.W. Armstrong, Rapid Commun. Mass Spectrom. 17 (2003) 553.

[31] Y.L. Li, M.L. Gross, J. Am. Soc. Mass Spectrom. 15 (2004) 1833.

[32] M. Zabet-Moghaddam, R. Krüger, E. Heinzle, A. Tholey, J. Mass Spectrom. 39 (2004) 1494.

[33] A. Berthod, J.J. Kozak, J.L. Anderson, J. Ding, D.W. Armstrong, Theor. Chem. Acc. 117 (2007) 127.

[34] D.W. Armstrong, L.F. He, Y.S. Liu, Anal. Chem. 71 (1999) 3873.

[35] J.L. Anderson, D.W. Armstrong, Anal. Chem. 75 (2003) 4851.

[36] M.L. Qi, D.W. Armstrong, Anal. Bioanal. Chem. 388 (2007) 889.

[37] A.W. Lantz, V. Pino, J.L. Anderson, D.W. Armstrong, J. Chromatogr. A 1115 (2006) 217.

[38] J. Ding, T. Welton, D.W. Armstrong, Anal. Chem. 76 (2004) 6819.

[39] X. Han, D.W. Armstrong, Acc. Chem. Res. 40 (2007) 1079.

[40] G.A. Baker, S.N. Baker, S. Pandey, F.V. Bright, Analyst 130 (2005) 800.
[41] S. Pandey, Anal. Chim. Acta 556 (2006) 38.

[42] S.A. Shamsi, N.D. Danielson, J. Sep. Sci. 30 (2007) 1729.

[43] Y.N. Hsieh, W.Y. Ho, R.S. Horng, P.C. Huang, C.Y. Hsu, H.H. Huang, C.H. Kuei, Chromatographia 66 (2007) 607.

[44] A. Berthod, L. He, D.W. Armstrong, Chromatographia 53 (2001) 63.

[45] J.L. Anderson, D.W. Armstrong, Anal. Chem. 77 (2005) 6453.

[46] K. Huang, X. Han, X. Zhang, D.W. Armstrong, Anal. Bioanal. Chem. 389 (2007) 2265.

[47] Z.S. Breitbach, D.W. Armstrong, Anal. Bioanal. Chem. 390 (2008) 1605.

[48] J. Barberá, E. Cavero, M. Lehmann, J.L. Serrano, T. Sierra, J.T. Vázquez, J. Am. Chem. Soc. 125 (2003) 4527.

[49] T.K. Chakraborty, G.V. Reddy, J. Org. Chem. 57 (1992) 5462.

[50] H. Tamiaki, T. Obata, Y. Azefu, K. Toma, Bull. Chem. Soc. Jpn. 74 (2001) 733.

[51] M.P. Denieul, B. Laursen, R. Hazell, T. Skrydstrup, J. Org. Chem. 65 (2000) 6052

[52] K. Nishikawa, S.L. Wang, H. Katayanagi, S. Hayashi, H.O. Hamaguchi, Y. Koga, K.I. Tozaki, J. Phys. Chem. B 111 (2007) 4894.

[53] H.L. Ngo, K. LeCompte, L. Hargens, A.B. McEwen, Thermochim. Acta 357 (2000) 97.

[54] J.G. Huddleston, A.E. Visser, W.M. Reichert, H.D. Willauer, G.A. Broker, R.D. Rogers, Green Chem. 3 (2001) 156.

[55] J.D. Holbrey, K.R. Seddon, Dalton Trans. (1999) 2133.

[56] E. Tas, M. Aslanoglu, A. Kilic, Z. Kara, J. Coord. Chem. 59 (2006) 861

[57] R.P. Tuffin, K.J. Toyne, J.W. Goodby, J. Mater. Chem. 6 (1996) 1271.

[58] U. Pyell, S. Schober, G. Stork, Fresenius J. Anal. Chem. 359 (1997) 538.

[59] J.A. Cabeza, I. del Rio, J.M. Fernández-Colinas, P. Garcia-Alvarez, D. Miguel, Organometallics 26 (2007) 1414.

[60] M. Piacenza, S. Grimme, J. Am. Chem. Soc. 127 (2005) 14841.

[61] J.L. Anderson, J. Ding, T. Welton, D.W. Armstrong, J. Am. Chem. Soc. 124 (2002) 14247. 